\title{
Advancement in Forging Process: A Review
}

\author{
Shalok Bharti \\ Shri Mata Vaishno Devi University, School of Mechanical Engineering, Katra, J\&K, India
}

\begin{abstract}
Forging is the technology of shaping the metal piece into the desired shape. This technology is widely used in the industry for making the well-defined shape of the metal. From using the simple hammer and anvil in the 12th century for making a simple shape to making the complex shape in present times forging witnessed the various advancements in its ways. In the recent times, there had seen much advancement in the processes of forging technology. In this review paper, various processes are discussed which bring the revolution in the field of forging technology.
\end{abstract}

Keywords: Forging, Advancement, Metal forming, Process

\section{Introduction}

Forging is the science in which the shaping of the metal is done by using the compressive forces. It is of three main types' i.e. Cold forging, Warm forging and hot forging depending upon the temperature at which they are done. Forging parts are used since the early ages but during the industrial revolution the demand of forged parts increases which result in the development of the new technology to increase the production as well as the quality of the material. In today's scenario forged parts are considered as the better parts than the parts done through casting because of its properties (grain flow). In this paper, the main concentration is about the advancement in the field of the forging process.

\section{Advantage}

In forging we can use various alloys in the process e.g. Aluminum alloys, Copper alloys, Magnesium alloys, Carbon and low alloy steels, Nickel alloys, Titanium alloys etc. In the process of shaping the material, Forging provides the greater strength and toughness, reduction in weight of the finished part, saving in the materials etc advantage. The parts of cast iron which are made up of casting process are brittle and weak in tension which cannot be subjected to high stresses. Hence, in place of the casting process, we use the forging process. Besides other factor cost is also one of the main factors. Forging process is somewhat cheaper than the casting process.

\section{Forging in Early Stages}

In the early stages, most of the forging was done by the blacksmiths by their hands using hammer and anvil and some of the blacksmiths also used some other type of energy like the hydraulic energy in their work. Some of the hand forging tools include Anvil, Swage Block, Tongs, Hammer, Hot Sett, Swages, Set hammer, Heading tool, Fullers, Flatters, Punches and drifts, Calipers, Blacksmith gauge etc. Besides the hand forging tools smiths also uses heating furnaces to heat the work piece to proper temperature so that it can be successful deformed to the desired shape. There are different types of furnaces that are in use. Some of them are Blacksmith forge, Continuous and batch type furnaces, Box type furnaces, Muffle type furnaces, Electric resistance heated furnaces etc.

\section{Forging Process}

Now a day, there are different types of processes which are available for forging. Depending upon the ease of use and considering the various aspects, one can choose the respective process for forging.

\subsection{Smith Forging}

Smith forging is done by hands on an anvil. It is considered only with the shaping of the small number of lightweight forgings. Some of the principal operations in Smith forging includes Upsetting, Drawing down, Bending, Cutting, Punching and drifting, Fullering, Setting down, Flatting, Swaging, Forge welding etc[1].

\subsubsection{Upsetting or Jumping}

This type of smith forging is used to increase the thickness or the bar's diameter and hence reduce its length. This type of method is used only in some of the cases such as in forming the bolt head etc. In this process, the area which is required to be upset is heated locally and the rest of the area is quenched in water so that the other area doesn't get affected by the process. This type of process is done very carefully and it is kept in mind that the other part of the material doesn't get bent or deformed.

\subsubsection{Drawing Down}

Drawing process is just the opposite of the upsetting process in which the thickness of the bar is reduced and hence increase its length. It is done by keeping the metal over the horn of the anvil and then hammering it on the face of the anvil.

\subsubsection{Bending}

Bending is a very common process in forging. This type of the operation is used to give the turn to the metal piece [2]. The bending of the piece of metal is done by giving the support to piece of metal on the anvil and then strike its free end with a compressive force e.g. hammer.

\subsubsection{Cutting}

The cutting process is another common process in which the red-hot metal is cut into pieces with the help of chisel and. Now a day's diamond cutting tools are also used for this process [3]. 


\section{International Journal of Science and Research (IJSR) \\ ISSN (Online): 2319-7064}

Index Copernicus Value (2016): 79.57 | Impact Factor (2015): 6.391

Beside the above mentioned traditional process in forging, there are wide ranges of forging process which can be applied to a metal according to the need of the forging. There are Punching and drifting, Fullering, Setting down, Flatting, Swaging, Forge welding etc processes which are available.

\subsection{Open Die Forging}

In open die forging relatively simple tooling is employed and the working to shape is gradual, employing a step-wise process. The operation consists of numerous squeezes or blows applied to portions of the piece and of in-between movements of the pieces as a whole to present further material to the tools [7]. In this type of forging process, the work piece get strike with the help of hammer. The work piece is kept on the anvil in this process. In it the upper die act as a hammer and in case of hot forging the molten metal can flow outside the die but only from the place where the die is not in the contact of hammer. In it the operator has to be very careful and have to keep changing the position of work piece from time to time.

\subsection{Impression-die forging}

Impression Die Forging is also sometimes known as Closed Die forging. In this process the work piece is kept in the die whose shape is exactly like the final product. So we can say that the die act as a mold. In most cases there are two types of die which are used in this process i.e. Upper die and the Lower die. The upper die is attached to the hammer whereas the Lower die is attached to the anvil. When the hammer or ram strikes the metal, then the metal fills the whole cavity. In it the hammer is in contact with the metal for only some milliseconds. For the bigger work piece multiple strikes are provided with the hammer but only for some milliseconds. The extra material which comes out in this process is called flash. When this flash comes out of the die then it become cold and do not allow the molten metal to come out of the die. Due to this reason the flash is trimmed off in this process. Impression die forging is practices both in the hot and cold state, using hammers as well as presses.

\subsection{Press Forging}

In press forging, slow and continuous force is applied over the work piece. In it the time calculated for the contact between die and work piece is calculated in seconds. Press forging can completely deform the work piece both from exterior as well as interior as compared to the hammer forging. We can say that the Press forging is the variation of the drop forging. The press forging process, which has considerable potential because of its competitive productivity and performance, recently emerges as an alternative process in the manufacture of thin-walled magnesium-alloy electronics components. Different from the traditional forging processes using bulk material as blanks, the press forging process squeezes a thick sheet in the thickness direction to provide enough material to form the embossments [8]. Press forging can also be done in the set up of impression die forging. In it there is a chance of cracks in the process due to which the heated dies are used in it.

\subsection{Upset Forging}

In the upset forging the diameter of the work piece is increased and its length is compressed. In it the initial work piece will be in the shape of a wire or rod. Some of the upset forging machines can also work over the diameter of 10 inches. In it the multiple dies are used having multiple cavities. If in every cycle, every cavity is filled then we will get the finished product in each cycle which is generally used in the mass production. The analytical research works on upset forging; of cylindrical billets have been reported by a number of researchers. Most of these analyses have been mainly concerned with the upset forging problems having the same: frictional conditions at the top and bottom die surfaces. Recently upset forging of cylindrical billets having dissimilar frictional conditions at two die surfaces has been treated by a few research workers [9].

\subsection{Roll Forging}

Roll-forging is an efficient way to produce long or thin metal parts, and the design of rolling die is a sophisticated problem due to the complex relative motions of dies and forging piece [10]. In it the thick section of metal is drawn into long, slender sections of uniform as well as non uniform diameter. Parts such as knife blades, automobile drive shafts, axles, leaf springs and gear-shift levers are made in this way. Roll forging process consists of placing raw stock between two roll dies which are of semi-cylindrical form and which are grooved to impart a desired shape to the piece being forged. The roll dies are carried on roll shafts and rotate continuously toward the operator. Roll forging may also be employed to make reductions in the cross-section and distribution of the metal of a billet, thus saving considerable work in the forging hammer or press [1].

\subsection{Cold Forging}

Cold forging is used in mechanical or hydraulic presses on low carbon as well as low alloy steels. This process is limited to axi-symmetric components formed by the combination of extrusion and upsetting techniques. Small parts such as nails, rivets etc. can be produced in large quantities from continuous wire stock. As compared to hot forging, cold forging can be made without draft and to closer tolerances than hot forgings, often resulting in considerable reduction in subsequent machining.

\subsection{High energy rate forging (HERF)}

High energy rate forging is the forging process in which the considerable large amount of energy is provided over the work piece in a very short interval of time. In this process the forging is done very quickly due to which the final product is ductile in nature. High energy rate forming (or forging) machines are principally used for forging, although they can also be used for cold forging. It is basically based on the same principles as are drop hammers and impact forging machines. They provide greater energies for a given ram weight by using ram velocities of the order of 2 to 10 times those of hammers. High energy rate forming equipment is based basically upon three methods of releasing energy:

Volume 6 Issue 12, December 2017 


\section{International Journal of Science and Research (IJSR) \\ ISSN (Online): 2319-7064}

Index Copernicus Value (2016): 79.57 | Impact Factor (2015): 6.391

1) Explosive Forming

2) Electro Magnetic Forming

3) Electro Hydraulic Forming [11].

\section{Forging Hammers}

These are used to forge the small parts. To forge the large parts, continuous blows or gradually applied pressure is required which is not possible for the hand forgings. Hence forging hammers came into existence which works on the same principle of providing continuous blows to the metal piece in order to get the large parts forgings. Nowadays the tradition of Pneumatic forging hammer is also in use. The pneumatic forging hammer mallet is one of most highly loaded parts in machinery and is made by forging, using the low alloyed steel for tempering Č4731 - JUS C.B9.021 (34CrMo4 - EN 10083/1) [4].

There are various types of forging hammers available to us like Spring hammer, Drop hammer, Counterblow hammer, Air or Steam hammer, Pneumatic hammer [1].

\subsection{Spring hammer}

This is used in the drawing out operation. In this type of mechanical hammers, the power is generated by the coil and recoil of a spring-loaded handle. The power can also be generated by using the compressed air. In this process, there is a hammer frame which supports the bearing in which oscillates the leaf spring as the connecting rod moves up and down when the sheave which is connected to the crank gear commences rotating [1]. As the spring oscillates, the ram moves up and down between the guides and strikes the job placed on the anvil.

\subsection{Drop hammer}

In it the specified industrial hammer is used to hit the metal part from a height and then shape the metal part into desired shape. This industrial hammer is placed into a large cylinder and a piston like structure is used to slide the hammer into the cylinder. This type of process is used to forge the large parts. It is observed that by using this method forging from alloy AZ31 with application of die hammer and without tools heating is possible. Although the temperature and velocity conditions are not favorable, products of good quality can be obtained by means of this technology [6].

Beside the above mentioned techniques of forging hammer there are various other type of hammer techniques also namely: Counterblow Hammer technique, Air and Steam Hammers technique, Pneumatic Hammer technique also which are widely used.

\section{Forging Presses}

The forging Presses are generally used for Press Forging. The following forging presses are available to produce close die forgings:

1) Mechanical Forging Presses

2) Hydraulic forging Presses

3) Screw Presses

\subsection{Mechanical Forging Presses}

Mechanical Presses make use of an electric motor to drive a large flywheel, which in turn drives the ram of the press through an eccentric (or crankshaft). All the mechanism is contained in a heavy, rigid frame which holds the ram guides, a clutch to disengage the flywheel and a brake to stop the (crankshaft or) eccentric shaft at the end of forging stock are important features of all mechanical forging presses. Such presses can operate on a continuing repetitive cycle at speeds varying from 100 strokes per minute on small presses to approximately 35 strokes per minutes on very large presses. Mechanical forging presses are designed for precision die forging and calibrating large series, large dimensions and power demanding forgings. Forming is carried out in several die cavities with increasing complexity, for example, intended for the aerospace and automotive industries. Transfer of vertical forging press workforce is realized between crankshaft and ram through the inserted connecting rod and coupling or sliding joint. The accuracy of these presses is directly related to their stiffness [5].

\subsection{Hydraulic Forging Presses}

Hydraulic presses are advantageous for the stamping of hollow forgings from the plate stock instead of from ingots or rolled shapes, as used for hammer forgings [1]. Hydraulic presses for closed die forging work are best suited to the forging of materials with relatively low forging temperatures such as aluminium and magnesium. Hydraulic presses are capable of forging work far beyond the capacity of steam hammers. A pressing action is capable of penetrating more deeply into the interiors of large work pieces.

\subsection{Screw Forging Press}

A screw press is generally used for bending and straightening operations and also for upsetting bolt heads. In it the ram is driven in upward and downward with the help of a screw. The shaft of the screw can be controlled with the help of a handle. The screw passes through a nut fitted near the top of the frame. The head of the screw is connected to the flywheel and the tail end of the screw joins with the ram which reciprocates between the ram guides. By making one or other of the discs to touch the flywheel, the screw can be made to rotate clockwise or anticlockwise, thus raising or lowering the ram.

\section{Conclusion}

In this review study it is concluded that the modern methods of shaping the metal is changing in a great pace. The modern forging processes are very useful and play a very vital role in the modern industry. Whether we use a simple hammer or we use the modern technique such as high energy rate forging, all the processes are applied to shape the metal into desired shape but the modern techniques saves our valuable time and provide us the final product with better dimensional accuracy and finish. Also it is found that there are fewer chances of defects in the modern forging techniques and we can also forge the bigger sized work 


\section{International Journal of Science and Research (IJSR) \\ ISSN (Online): 2319-7064}

Index Copernicus Value (2016): 79.57 | Impact Factor (2015): 6.391

piece which was never possible with the traditional forging techniques.

\section{References}

[1] A Text Book of Production Technology, O.P. Khanna, M. Lal; Dhanpat Rai Publication, pp. 16.24 - 16.31, 16.49, 16.53.

[2] Forging operations www.engineeringhut.blogspot.in/2010/10/forgingoperations.html

[3] Processing of Diamond Composites for Cutting Tools by Powder Metallurgy and Rotary Forging - Marcello Filgueira and Daltro Garcia Pinatti

[4] Reparation of the Damaged Forging Hammer Mallet by Hard Facing and Weld Cladding - Vukić Lazić, Srbislav Aleksandrović, Dragan Milosavljević Rajko Čukić, Aleksandard Sedmak, Vencislav Grabulov

[5] Optimization of power Transmission on Mechanical Forging Presses; Zdenek Chval, Milan Cechura, pp 890-896

[6] Hammer Forging Process Of Lever Drop Forging From Az31 Magnesium Alloy - A. Gontarz, Z. Pater, K. Drozdowski - Metabk 52(3) 359-362 (2013)

[7] Metal Forming; Open Die Forging - A.Tomlinson, pp 19-25

[8] A study of flow-through phenomenon in the press forging of magnesium-alloy sheets - Fuh-Kuo Chen, Tyng-Bin Huang, Shou-Jung Wang

[9] Analysis of upset forging of cylindrical billets considering the dissimilar frictional conditions at two flat die surfaces - D. Y. YANG, Y. CHOI and J. H. KIM, pp 397-404

[10] Precision design of Roll-Forging Die and its application in the forming of automobile front axles Zhong-YiCai, pp 95-101

[11] NPTEL, Metal Forming \& Powder Metallurgy, Lect. 9, Prof. H.S. Shan

\section{Author Profile}

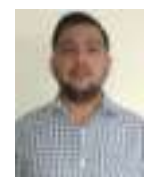

Shalok Bharti received the B.Tech degree in Mechanical Engineering from Sri Sai College of Engg \& Tech., Pathankot in 2016 and currently he is doing his M.Tech Degree in Manufacturing and Automation from Shri Mata Vaishno Devi University, Katra under the supervision of Mr. Ankush Raina. 